ISSN 0103-9954

\title{
QUALIDADE DOS TANINOS DE JUREMA-PRETA (Mimosa tenuiflora) PARA A PRODUÇÃO DE ADESIVO TANINO FORMALDEÍDO
}

\author{
Mimosa tenuiflora TANNIN QUALITY FOR THE PRODUCTION OF TANNIN FORMALDEHYDE \\ ADHESIVE
}

\author{
Tatiane Kelly Barbosa de Azevêdo ${ }^{1}$ Juarez Benigno Paes ${ }^{2}$ Leandro Calegari ${ }^{3}$ \\ José Wallace Barbosa do Nascimento ${ }^{4}$
}

\begin{abstract}
RESUMO
A jurema-preta (Mimosa tenuiflora), espécie abundante no semiárido brasileiro, tem potencial para a produção de taninos, havendo a necessidade de pesquisas que indiquem as melhores formas de aplicação dos mesmos. Este estudo objetivou avaliar a qualidade dos taninos da jurema-preta para a produção de adesivo tanino formaldeído com o período de coleta da planta. Foram realizadas coletas de casca nos meses de agosto e dezembro de 2008 e em abril e agosto de 2009, na Fazenda Lameirão, Santa Terezinha, Paraíba, sendo coletadas 10 plantas por período, totalizando 40 plantas. As cascas foram retiradas do tronco e galhos de diâmetro de até $3,0 \mathrm{~cm}$, moídas em moinho de facas e classificadas em peneiras e empregadas para a extração de taninos, partículas inferiores a $1,0 \times 2,0 \mathrm{~cm}$ e superiores a $0,2 \times 0,2 \mathrm{~cm}$. Os extratos tânicos para a produção de adesivos foram extraídos em água destilada em uma autoclave na temperatura de ebulição da água à pressão atmosférica, concentrados por evaporação ao ar livre e mantidos em estufa a $70 \pm 3^{\circ} \mathrm{C}$, até a completa evaporação da umidade. Foram avaliados o teor de sólidos totais, índice de Stiasny e teor de taninos condensados nas cascas. Para produzir os adesivos, foi realizada a sulfitação ácida dos taninos obtidos. Houve influência do período de coleta das plantas no teor de taninos condensados. Foi encontrado nos adesivos produzidos com os taninos de jurema-preta, valor de teor sólido semelhante aos da acácianegra (Acacia mearnsii), não havendo diferença significativa entre os períodos de coleta para o teor sólidos e tempo de gelatinização dos adesivos. Porém, o período de coleta influenciou o pH e a viscosidade dos adesivos. Os adesivos produzidos tiveram viscosidade elevada, indicando a necessidade de pesquisas para a melhoria dos mesmos.
\end{abstract}

Palavras-chave: espécie da Caatinga; taninos condensados; características dos adesivos.

\section{ABSTRACT}

Mimosa tenuiflora is an abundant species in the Brazilian semi-arid region which offers potential for the tannin production but need research indicating the best ways of its application. This study aimed to evaluate the quality of tannin from Mimosa tenuiflora for the formaldehyde tannin adhesive production with the plant collection period. The bark collections were carried out in the months of August and December of 2008 and in April and August of 2009, in Lameirão farm, in municipality of Santa Terezinha, Paraíba state,

1 Engenheira Florestal, Dra., Programa de Pós Graduação em Ciências Florestais, Universidade Federal Rural de Pernambuco, Rua Dom Manuel de Medeiros, s/n, Bairro Dois Irmãos, CEP 52171-900, Recife (PE), Brasil. tatianekellyengenheira@hotmail.com

2 Engenheiro Florestal, Dr., Professor do Departamento de Ciências Florestais e da Madeira, Centro de Ciências Agrárias, Universidade Federal do Espírito Santo, Av. Governador Lindemberg, 316, Bairro Centro, CEP 29550000, Jerônimo Monteiro (ES), Brasil. jbp2@uol.com.br

3 Engenheiro Florestal, Dr., Professor da Unidade Acadêmica de Engenharia Florestal, Centro de Saúde e Tecnologia Rural, Universidade Federal de Campina Grande, Campus de Patos, Cx. Postal, 64, CEP 58700-970, Patos (PB), Brasil. leandrocalegari@yahoo.com.br

4 Engenheiro Agrícola, Dr., Professor da Unidade Acadêmica de Engenharia Agrícola, Centro de Tecnologia e Recursos Naturais, Universidade Federal de Campina Grande, Av. Aprígio Veloso, 882, Bloco CK, Bodocongó, CEP 58429-140, Campina Grande (PB), Brasil. wallace@deag.ufcg.edu.br 
Brazil, being collected 10 plants per period, totaling 40 plants. The barks were taken from the trunk and branches up to $3.0 \mathrm{~cm}$ in diameter, ground into mill knives and classified in sieves, having been employed for the extraction of tannins, particles less than $1.0 \times 2.0 \mathrm{~cm}$ and superior than $0.2 \times 0.2 \mathrm{~cm}$. The extract tannic for the adhesives production was extracted in distilled water in an autoclave at boiling temperature of water at atmospheric pressure, concentrated by evaporation and kept in an oven at $70 \pm 3{ }^{\circ} \mathrm{C}$ until the complete evaporation of moisture, and was evaluated the total solid content, Stiasny's index and condensed tannin content in the bark by collection period. To produce the adhesives, an acid sulphitation of tannins was obtained. There was influence of period of collection of the plants in condensed tannin contents. It was found in adhesives produced with the tannins of Mimosa tenuiflora, solid content values, similar to those of Acacia mearnsii, no significant difference between collection periods for the solid content and gelatinization time of adhesives was obtained. However, the collection period influenced the $\mathrm{pH}$ and viscosity of adhesives. The adhesives produced showed high viscosity, indicating the need for research to improve the adhesives produced.

Keywords: species from Caatinga; condensed tannins; characteristics of adhesive.

\section{INTRODUÇÃO}

Os taninos vegetais, conhecidos por taninos naturais, podem ser encontrados em várias partes do vegetal, como no cerne da madeira, casca, frutos e sementes (PAES et al., 2010). Normalmente, os frutos verdes têm alta concentração de taninos, que decresce à medida que eles amadurecem (BOTREL et al., 2002; PRILL, 2011).

Nos vegetais, os taninos têm a função de defesa e proteção. Em virtude de sua adstringência, eles impedem o ataque de herbívoros a determinados locais da planta, como frutos, sementes e casca. Segundo Monteiro et al. (2006), esses compostos são responsáveis pela adstringência de muitos frutos e produtos vegetais, em virtude da precipitação de glucoproteínas salivares, resultando na perda do poder lubrificante. Graças a sua comprovada atividade antimicrobiana, acredita-se que os taninos atuem na proteção do vegetal contra o ataque de microorganismos patogênicos (VITAL et al., 2001; COLLI et al., 2007).

Os taninos vegetais são constituídos por polifenóis e classificados em hidrolisáveis e condensados. Os taninos hidrolisáveis são poliésteres da glicose e classificados, dependendo do ácido formado de sua hidrólise, em taninos gálicos ou taninos elágicos, enquanto os condensados são constituídos por monômeros do tipo catequina e conhecidos por flavonoides (PIZZI, 1993). Monteiro et al. (2006) afirmaram que os taninos são compostos fenólicos de grande interesse econômico e ecológico.

As espécies florestais mais utilizadas na produção comercial de taninos são as cascas de acácia-negra (Acacia mearnsii) e o cerne do quebracho (Schinopsis sp.). Além dessas espécies, Paes et al. (2006b) citaram como grandes produtoras de tanino o Eucalyptus astringens (casca contendo de 40 a $50 \%$ de taninos), o mangue-vermelho e o mangue-branco, respectivamente Rhizophora candelaria e Rhizophora mangle (casca com 20 a $30 \%$ de taninos).

Os taninos são de grande importância no curtimento e recurtimento de peles, são utilizados pela indústria de petróleo, como agente dispersante para controlar a viscosidade de argilas na perfuração de poços (PAES et al., 2006a; TANAC S.A., 2013), sendo, também, empregados no tratamento de água de abastecimento e residuárias (SILVA, 1999; PELEGRINO, 2011; KLUMB e FARIA, 2013; TANAC S.A., 2013), na fabricação de tintas e adesivos para madeira e derivados (TRUGILHO et al., 1997) e, em virtude de suas propriedades antissépticas, vêm sendo testados contra organismos xilófagos (VITAL et al., 2001; TRUGILHO et al., 2003; COLLI et al., 2007).

As pesquisas sobre os adesivos de taninos foram iniciadas na década de 1950, na Austrália, Indonésia, Índia, Venezuela e nos Estados Unidos, porém, o crescente interesse pelo desenvolvimento de adesivos, a partir de fontes naturais, foi somente após a crise do petróleo, cuja primeira fase ocorreu em 1956 e a última no ano de 2008 (GONÇALVES e LELIS, 2001). Os taninos podem representar de 2 a $40 \%$ da massa seca da casca de várias espécies florestais.

Para Gonçalves e Lelis (2001) são importantes as pesquisas que buscam matériasprimas alternativas para a indústria de painéis, porque o custo de aquisição de adesivos sintéticos representa um componente de peso no custo total 
do produto. Desta forma, vêm sendo desenvolvidas várias pesquisa para o emprego dos taninos como adesivos para madeira e derivados (VÁZQUEZ et al., 2005; GONÇALVES et al., 2008; ALMEIDA et al., 2010; MOUBARIK et al., 2010; CARNEIRO et al., 2009; 2012), e em países como África do Sul, Finlândia e Nova Zelândia os taninos vegetais são empregados como matéria-prima para produção de adesivos para a indústria madeireira (CARNEIRO et al., 2009; 2012).

Neste contexto, o presente estudo teve como objetivo avaliar a qualidade dos taninos de jurema-preta (Mimosa tenuiflora (Willd.) Poir.) para a produção de adesivos tanino formaldeído em função da variação nas coletas das cascas (estação seca e chuvosa).

\section{MATERIAL E MÉTODOS}

\section{Local de coleta e espécie estudada}

As árvores de jurema-preta (Mimosa tenuiflora (Willd.) Poir.), que possuíam boa fitossanidade, foram selecionadas para o corte e retirada das cascas em uma mata nativa, na Fazenda Lameirão, de propriedade da Universidade Federal de Campina Grande (UFCG), localizada no Município de Santa Terezinha, Estado da Paraíba (Latitude S $7^{\circ}$, Longitude W $37^{\circ} 04^{\prime}$, altitude 240 metros e clima, segundo a classificação de Köppen, semiárido do tipo Aw' quente úmido, com chuvas de verão e, ou outono), a média anual das precipitações pluviométricas em torno de $600 \mathrm{~mm}$, distante 385 km de João Pessoa, Capital do Estado.

As cascas foram coletadas durante o período de estiagem e início das chuvas, ocorridos nos meses de agosto e dezembro de 2008 e, no término das chuvas e no período de estiagem, nos meses de abril e agosto de 2009, respectivamente, sendo 10 árvores amostradas por período, em parcela de 20 x 20 metros, alocadas aleatoriamente na área, totalizando 40 árvores.

\section{Preparo das cascas para extração dos taninos}

As cascas, ao serem retiradas, foram condicionadas em sacos plásticos, para que não houvesse perda de umidade e transportadas para o Laboratório de Tecnologia de Produtos Florestais (LTPF) da Universidade Federal de Campina Grande (UFCG), Centro de Saúde e Tecnologia Rural (CSTR), localizado em Patos - PB. Depois de pesadas, foram secas ao ar e moídas em um moinho de facas, para obter um material de menor granulometria.

As cascas moídas foram classificadas, sendo utilizada no estudo a porção que passou por uma peneira de malha de 1,0 x 2,0 cm (existente no moinho de facas) e ficou retida em peneira de 0,2 $\mathrm{x} 0,2 \mathrm{~cm}$. Após essa operação, retiraram-se quatro amostras representativas de cascas por período de coleta, aproximadamente $100 \mathrm{~g}$ cada. Duas destas amostras foram secas a $103 \pm 2{ }^{\circ} \mathrm{C}$ por 48 horas, a fim de avaliar o teor de umidade (base seca) das cascas secas ao ar livre e permitir os cálculos da quantidade de taninos presentes em cada amostra.

\section{Extrações para a quantificação de substâncias tânicas por período de coleta}

Para a quantificação das substâncias tânicas, foram tomadas, de cada amostra remanescente, três porções de $25 \mathrm{~g}$ de material seco. As amostras foram transferidas para balões de fundo chato com capacidade de $500 \mathrm{~mL}$, em que foram adicionados $250 \mathrm{~mL}$ de água destilada (relação 1:10) e submetidas à fervura sob refluxo por duas horas. Cada amostra foi submetida a duas extrações, a fim de se retirar a máxima quantidade de extrativos presentes. Assim, a relação material:solução passou a ser de 1:20.

Após cada extração, o material foi passado em uma peneira de 150 "mesh", e em um tecido de flanela, para a retenção de partículas finas. O extrato obtido foi homogeneizado e filtrado em funil de vidro sinterizado de porosidade 2. Em seguida foi concentrado para $250 \mathrm{~mL}$, pela evaporação da água ao empregar um aparelho tipo Soxhlet e retiradas três alíquotas (amostras) de $50 \mathrm{~mL}$ de cada extrato, duas delas foram utilizadas para a determinação do teor de taninos condensados (TTC), e uma foi evaporada em estufa a $103 \pm 2^{\circ} \mathrm{C}$ por 48 horas, para a determinação da porcentagem de teor de sólidos totais (TST).

Para a determinação do TTC presente em cada amostra foi empregado o método de Stiasny, descrito por Guangcheng et al. (1991), com algumas modificações. Para tanto, aos $50 \mathrm{~mL}$ do extrato bruto foram adicionados $4 \mathrm{~mL}$ de formaldeído $(37 \%$ $\mathrm{m} / \mathrm{m}$ ) e $1 \mathrm{~mL}$ de ácido clorídrico concentrado. Cada mistura foi submetida à fervura sob refluxo por 30 minutos. Nestas condições, os taninos formam complexos insolúveis que podem ser separados por filtragem simples. Para este caso, empregou-se filtro de papel posto em funil de Büchner de $10 \mathrm{~cm}$ de 
diâmetro e $4 \mathrm{~cm}$ de profundidade. $\mathrm{O}$ material retido no filtro foi seco em estufa a $103 \pm 2^{\circ} \mathrm{C}$ por 24 horas, pesado e calculado o índice de Stiasny. A quantidade de taninos presente em cada amostra foi obtida ao se multiplicar o Índice de Stiasny pelo teor de sólidos totais e o teor de não taninos pela diferença entre o TST e TTC. Todas as análises foram realizadas em triplicatas, empregando-se as metodologias citadas por Trugilho et al. (2003); Paes et al. (2006a; 2006b) e Paes et al. (2010).

\section{Extrações das substâncias tânicas para a produção de adesivos}

Para a produção dos adesivos, para cada 2,0 $\mathrm{kg}$ de casca foram adicionados $10 \mathrm{~L}$ de água destilada (relação 5:1). As extrações ocorrem à temperatura de ebulição da água e pressão ambiente, em uma autoclave com capacidade de 48 litros, dentro de um recipiente cilíndrico, confeccionado em aço inox, com capacidade de, aproximadamente, $30 \mathrm{~L}$ (diâmetro de $30,50 \mathrm{~cm}$ e altura de $40 \mathrm{~cm}$ ).

Cada amostra de casca foi submetida a duas extrações, com duração de duas horas cada, totalizando quatro horas, a fim de se retirar a máxima quantidade de extratos tânicos. Assim, a relação final casca:solução foi de 1:10. Após cada extração, o material foi filtrado em um filtro adaptado, com diâmetro de $30 \mathrm{~cm}$ e profundidade de $80 \mathrm{~cm}$, confeccionado em tecido grosso (jeans), sendo o extrato obtido novamente filtrado em peneira confeccionada com tecido de silkscreen e, posteriormente em peneira de 150 mesh, para a retenção de partículas finas de casca.

$\mathrm{O}$ extrato obtido foi homogeneizado e transportado para bandejas de alumínio de $5 \times 40 \mathrm{x}$ $60 \mathrm{~cm}$, encaminhado para a evaporação ao ar livre até atingir $\pm 50 \%$ de sólidos e conduzido a uma estufa de ventilação forçada mantida a $70 \pm 3^{\circ} \mathrm{C}$, até a completa evaporação da umidade. $\mathrm{O}$ material anidro foi moído em um multiprocessador de alimentos, de uso domestico, e classificado em peneira de 60 mesh para posterior produção do adesivo.

\section{Produção de adesivo tanino formaldeído}

O adesivo tanino formaldeído foi produzido no Laboratório de Tecnologia de Produtos Florestais (LTPF) da Universidade Federal de Viçosa (UFV), Viçosa - MG. Para tanto, as amostras de taninos foram submetidas a um pulverizador até obter uma granulometria de 100 mesh. Para produzir os adesivos, foi realizada a sulfitação ácida dos taninos ao serem empregados $75 \mathrm{~g}$ de taninos, $75 \mathrm{~g}$ de água, $5 \mathrm{~mL}$ de ácido clorídrico $(10 \mathrm{~N})$, e $5 \%$ de sulfito de sódio (em relação à massa de tanino empregada, $3,75 \mathrm{~g}$ ). Este material foi misturado e mantido a uma temperatura de $110^{\circ} \mathrm{C}$, durante um período de $1 \mathrm{~h}$.

Para a produção dos adesivos, as soluções contendo os taninos sulfitados foram misturadas com o agente endurecedor formaldeído em um Becker de $1000 \mathrm{~mL}$, sendo a mistura agitada com um bastão de vidro durante um minuto, para que ocorresse a reação com o endurecedor.

\section{Propriedades dos adesivos produzidos}

O teor de sólidos dos adesivos foi calculado de acordo com Moslemi (1974), ao evaporar a água das amostras, contendo $3 \mathrm{~g}$ de adesivo, que foram levados à estufa até atingirem massa constante. Já o tempo de gelatinização foi obtido com amostras de $1,0 \mathrm{~g}$ do adesivo, que foram colocadas em tubos de ensaio de $15 \mathrm{~cm}$ de altura e $2 \mathrm{~cm}$ de diâmetro, em cujo interior foi mergulhado um bastão de vidro. $\mathrm{O}$ conjunto tubo-bastão foi aquecido até $170^{\circ} \mathrm{C}$, cronometrando-se o tempo gasto para polimerização do adesivo (Figura 1).

A viscosidade foi obtida com o emprego de um viscosímetro tipo Brookfield- LV (Figura 2), sendo adotada de uma velocidade de rotação de 12 rpm, em amostras de aproximadamente $300 \mathrm{~mL}$. As análises para a quantificação do teor de sólidos, tempo de gelatinização e viscosidade dos adesivos foram realizadas em triplicatas.

O tempo de trabalho do adesivo foi determinado com o uso de um cronômetro acionado

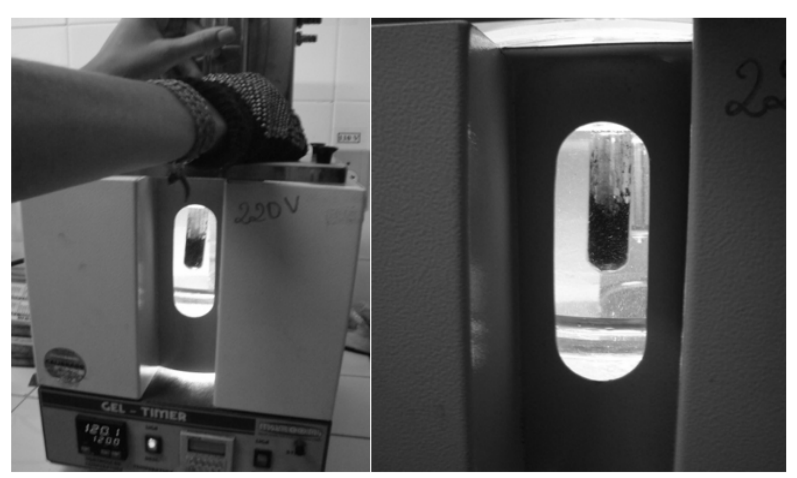

FIGURA 1: Gel-timer com amostras de adesivo de taninos vegetais.

FIGURE 1: Gel-timer with samples of vegetable tannin adhesive. 


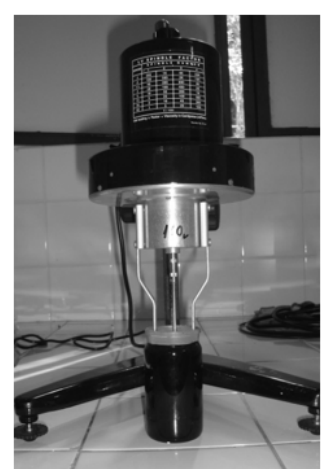

FIGURA 2: Viscosímetro Brookfield- LV com amostra.

FIGURE 2: Brookfield viscometer - LV with sample.

após a adição do agente endurecedor formaldeído. Para cada amostra, o tempo foi tomado até o endurecimento (cura) do adesivo. Para tanto, foram empregados $6 \mathrm{~mL}$ de formaldeído. Logo após a adição do formaldeído o $\mathrm{pH}$ da mistura foi mensurado. As análises foram realizadas com quatro repetições.

Os dados obtidos foram submetidos à análise de variância e a teste de média a 5\% de significância, ao serem comparadas as características dos adesivos produzidos com o período de coleta de cascas das árvores (estação seca e chuvosa).

\section{RESULTADOS E DISCUSSÃO}

$\mathrm{Na}$ Tabela 1 encontram-se os valores médios de teor de umidade em base seca das cascas ao serem coletadas, concentração de taninos, teor de sólidos totais, índice de Stiasny e teor de não taninos, presentes na casca de jurema-preta, por período de coleta. $\mathrm{O}$ maior teor de umidade em base seca na casca foi encontrado nos meses de dezembro de 2008 e abril de 2009. Estes foram os meses que as plantas estavam com maior percentual de folhas na copa, enquanto o menor teor de umidade foi encontrado no mês de agosto de 2008, período em que as plantas estavam desprovidas de folhas.

O teor de taninos condensados (TTC) foi maior no mês de dezembro de 2008, em que as plantas se encontravam com presença de folhas verdes. $\mathrm{O}$ menor teor de taninos condensados foi obtido no mês de agosto de 2009, o que deve ter ocorrido pela grande presença de frutos verdes neste período. Paes et al. (2010) observaram que o angico-vermelho (Anadenanthera colubrina var. cebil) possuía $10,69 \%$ de taninos nos frutos. Por essa razão, acredita-se que a planta utiliza de uma estratégia, em que os taninos são translocados da casca para os frutos, evitando assim o ataque de predadores, em função de suas propriedades antissépticas contra insetos xilófagos (VITAL et al., 2001), reduzindo o teor de taninos condensados presentes na casca.

$\mathrm{O}$ índice de Stiasny foi maior nos meses de agosto e dezembro de 2008 e menor em agosto de 2009. Já os teores de sólidos totais e de não taninos foram maiores entre dezembro de 2008 e abril de 2009 e menores em agosto de 2009. Isto indica que no período chuvoso as plantas encontram-se com folhas e início da floração, período em que foram observados por Paes et al. (2010), uma maior concentração de taninos nas cascas de angicovermelho.

Na Tabela 2 constam os valores médios das propriedades dos adesivos à base de tanino de jurema-preta para os diferentes períodos de obtenção das cascas. A análise de variância indicou que os teores de sólidos e o tempo de gelatinização dos adesivos obtidos dos extratos de jurema-preta não foram afetados pelo período de coleta das cascas. No entanto, o período de coleta interferiu no $\mathrm{pH}$ e

TABELA 1: Valores médios da umidade, teor de sólidos totais (TST), índice de Stiasny (I), teores de taninos condensados (TTC) e de não taninos (TNT) obtidos para as cascas de jurema-preta.

TABLE 1: Average values of moisture, total solid content (TST), Stiasny's index (I) and condensed tannins content (TTC) obtained for Mimosa tenuiflora barks.

\begin{tabular}{ccccccc}
\hline \multicolumn{2}{c}{ Período de Coleta } & Umidade (\%) & TST (\%) & I (\%) & TTC (\%) & TNT (\%) \\
\hline \multirow{2}{*}{2008} & Agosto & 47,62 & 25,20 & 69,84 & 17,60 & 7,60 \\
& Dezembro & 90,60 & 30,80 & 71,12 & 21,90 & 8,90 \\
\multirow{2}{*}{2009} & Abril & 83,50 & 29,40 & 67,35 & 19,80 & 9,60 \\
& Agosto & 67,22 & 24,25 & 65,70 & 16,04 & 8,21 \\
\hline
\end{tabular}


TABELA 2: Propriedades dos adesivos taninos formaldeído de jurema-preta sulfitados.

TABLE 2: Adhesives tannin formaldehyde properties of Mimosa tenuiflora sulfited.

Propriedades dos Adesivos Produzidos

Período de coleta

pH Tempo Reação (min.) $\quad$ Teores Sólidos (\%) $\quad \begin{gathered}\text { Tempo de } \\ \text { Gelatinização (s) }\end{gathered} \quad$ Viscosidade (cP)

\begin{tabular}{ccccccc}
\hline \multirow{2}{*}{2008} & Agosto & $5,76 \mathrm{a}$ & 30 & $46,8 \mathrm{a}$ & $153 \mathrm{a}$ & $10.000 \mathrm{a}$ \\
& Dezembro & $5,69 \mathrm{~b}$ & 30 & $46,9 \mathrm{a}$ & $164 \mathrm{a}$ & $2.067 \mathrm{c}$ \\
2009 & Abril & $5,40 \mathrm{~d}$ & 30 & $45,5 \mathrm{a}$ & $208 \mathrm{a}$ & $5.833 \mathrm{~b}$ \\
& Agosto & $5,47 \mathrm{c}$ & 30 & $44,0 \mathrm{a}$ & $197 \mathrm{a}$ & $10.000 \mathrm{a}$ \\
\hline
\end{tabular}

Em que: Médias seguidas por letras minúsculas iguais, na mesma coluna, não diferem entre si (Tukey, $\mathrm{P}>0,05$ ).

na viscosidade dos adesivos produzidos.

Teodoro e Lelis (2005) encontraram um teor sólido de 45,87\%, para o adesivo obtido da casca de acácia-negra (Acácia mearnsii) valor bem aproximado ao encontrado para a jurema-preta, indicando que os taninos de jurema-preta têm potencial para serem empregados na produção de adesivos.

Segundo Roffael e Dix (1994), o pH pode interferir no processo de endurecimento de uma resina sendo importante para o processo de colagem. Mori et al. (1999), ao trabalharem com casca de Eucalyptus grandis, verificaram que o aumento do $\mathrm{pH}$ acelerou o endurecimento dos extratos analisados. No entanto, nesta pesquisa, não foi observada a influência do $\mathrm{pH}$ no tempo de gelatinização dos adesivos produzidos.

Os taninos provenientes das cascas coletadas em agosto (período seco) produziram adesivos mais viscosos que aqueles obtidos de cascas coletadas em abril (término do período chuvoso) e dezembro (início do período chuvoso). Segundo Pizzi (1994), a alta viscosidade dos adesivos à base de taninos está relacionada à presença de gomas de alto peso molecular, que são responsáveis pela alta viscosidade, sendo característica do extrato tânico, produzindo assim, adesivos de pior qualidade. Com base nos resultados obtidos nesta pesquisa, para a produção de adesivos, a melhor época para a coleta das cascas de jurema-preta seria durante o período chuvoso na região.

Adesivos com uma viscosidade elevada $(>6.000 \mathrm{cP})$ dificultam o manuseio e sua aplicabilidade na madeira sólida, principalmente em painéis de madeira reconstituída. Segundo Mori et al. (2001), uma alta viscosidade torna os adesivos à base de taninos inadequados, uma vez que afeta diretamente a formulação, a aplicação e a resistência da linha de cola.

Assim, os valores de viscosidade observados indicam que os adesivos obtidos dos taninos de jurema-preta, principalmente os provenientes das cascas obtidas durante o período de estiagem, necessitam de modificações químicas, a fim de diminuir sua viscosidade e permitir seu emprego na indústria madeireira.

\section{CONCLUSÕES}

Os teores de sólidos e o tempo de gelatinização dos adesivos produzidos não foram influenciados pelas épocas de coleta da casca de jurema-preta.

$\mathrm{O} \mathrm{pH}$ dos adesivos foi influenciado pela época de coleta, porém, sem seguir um padrão quanto ao período seco (agosto-dezembro) ou chuvoso (dezembro-abril).

Os adesivos produzidos com os taninos de jurema-preta obtiveram teores de sólidos semelhantes aos encontrado na acácia-negra.

A viscosidade dos adesivos produzidos com os taninos de jurema-preta, obtidos das cascas coletadas durante a estação seca, foi alta, indicando que os mesmos devem passar por transformações químicas para que possam ser empregados na colagem de madeira.

\section{REFERÊNCIAS BIBLIOGRÁFICAS}

ALMEIDA, N. F. et al. Estudo da reatividade de taninos de folhas e cascas de barbatimão Stryphnodendron adstringens (Mart.) Coville. Scientia Forestalis, Piracicaba, v. 38, n. 87, p. 401-408, 2010.

BOTREL, N. et al. Inibição do amadurecimento da banana-'prata-anã' com a aplicação do 
1-metilciclopropeno. Revista Brasileira de Fruticultura, Jaboticabal, v. 24, n. 1, p. 53-56, 2002.

CARNEIRO, A. C. O. et al. Parâmetros cinéticos de adesivos produzidos a partir de taninos de Anadenanthera peregrina e Eucalyptus grandis. Revista Árvore, Viçosa, v. 36, n. 4, p. 767-775, 2012.

CARNEIRO, A. C. O. et al. Efeito da hidrólise ácida dos taninos de Eucalyptus grandis W. Hill ex Maiden nas propriedades dos adesivos tânicos. Revista Árvore, Viçosa, v. 33, n. 4, p. 733-739, 2009.

COLLI, A. et al. Propriedades físico-mecânicas e preservação, com boro e tanino, do Bambusa tuldoides (Munro). Floresta e Ambiente, Seropédica, v. 14, n. 1, p. 56 - 64, 2007.

GONÇALVES, C.A.; LELIS, C.R. Teores de tanino da casca e da madeira de cinco leguminosas arbóreas. Floresta e Ambiente, Seropédica, v. 8, n. 1, p. 167 - 173, 2001.

GONÇALVES, F. G.; LELIS, R. C. C.; OLIVEIRA, J. T. S. Influência da composição da resina taninouréia-formaldeído nas propriedades físicas e mecânicas de chapas aglomeradas. Revista Árvore, Viçosa, v. 32, n. 4, p. 715-722, 2008.

GUANGCHENG, Z.; YUNLU L.; YAZAKI, Y. Extractives yields, Stiasny values and polyflavanoid contents in barks from six Acacia species in Australian. Australian Forestry, Queen Victoria, v. 3, n. 54, p. 154-156, 1991.

KLUMB, A. K.; FARIA, O. L. V. Produção de coagulante vegetal catiônico a partir de cascas de eucalipto (Eucalyptus tereticornis). Vetor, Rio Grande, v. 22, n. 1, p. 71-80, 2012.

MONTEIRO, J. M. et al. The effects of seasonal climate changes in the Caatinga on tannin levels in Myracrodruon urundeuva (Engl.) Fr. All. and Anadenanthera colubrina (Vell.) Brenan. Revista Brasileira de Farmacognosia, João Pessoa, v. 16, n. 3, p. 338-344. 2006.

MORI, F. A. et al. Estudo de taninos da casca de Eucalyptus urophylla S.T. Bake para produção de adesivos. Revista Árvore, Viçosa, v. 25, n. 2, p. 257 - 263, 2001.

MORI, F. A. et al. Utilização de resinas à base de taninos das cascas de Eucalyptus grandis W. Hill ex Maiden na produção de painéis compensados. Revista Árvore, Viçosa, v. 23, p. 455 - 461, 1999. MOSLEMI, A. A. Particleboard: materials. London: Southern Illinois University, 1974. v. 1, $244 \mathrm{p}$.
MOUBARIK, A. et al. Preparation and mechanical characterization of particleboard made from maritime pine and glued with bio-adhesives based on cornstarch and tannins. Maderas. Ciencia y Tecnologia, Concepción, v. 12, n. 3, p. 189-197, 2010.

PAES, J. B. et al. Avaliação do potencial tanífero de seis espécies florestais de ocorrência no semi-árido brasileiro. Cerne, Lavras, v.12, n. 3, p.232 - 238, 2006a.

PAES, J. B. et al. Substâncias tânicas presentes em várias partes da árvore angico-vermelho (Anadenanthera colubrina (Vell.) Brenan. var. cebil (Gris.) Alts.). Scientia Forestalis, Piracicaba, v. 38, n. 87, p. $441-447,2010$.

PAES, J. B. et al. Viabilidade técnica dos taninos de quatro espécies florestais de ocorrência no semiárido brasileiro no curtimento de peles. Ciência Florestal, Santa Maria, v. 16, n. 4, p. 453-462, 2006b.

PELEGRINO, E.C.F. Emprego de coagulante à base de tanino em sistema de pós-tratamento de efluente de reator UASB por flotação. 2011. 155f. Dissertação (Mestrado em Hidráulica e Saneamento) - Universidade de São Paulo, Escola de Engenharia de São Carlos, São Carlos, 2011.

PIZZI, A. Advanced wood adhesives technology. New York: Marcell Dekker, 1994. 289 p.

PIZZI, A. Tannin-based adhesives. In: PIZZI, A. (Ed.). Wood adhesives: chemistry and technology. New York: Marcell Dekker, 1993. p. 77 - 246.

PRILL, M. A. S. Tecnologia pós-colheita de modificação atmosférica, controle de etileno e desverdeamento para a banana 'prataanã' cultivada em Boa Vista, Roraima. 2011. 112 f. Dissertação (Mestrado em Agronomia) Universidade Federal de Roraima, Boa Vista, 2011. ROFFAEL, E.; DIX, B. Tannine als Bindemittel für Holzwerkstoffe. Holz-Zentralblatt, Leinfelden, v. 120, n. 6, p. 90-93, 1994.

SILVA, T. S. S. Estudo de tratabilidade físicoquínica com uso de taninos vegetais em água de abastecimento e de esgoto. 1999. 87 f. Dissertação (Mestrado em Saúde Pública) - Fundação Oswaldo Cruz, Escola Nacional de Saúde Publica, Rio de Janeiro, 1999.

TANAC S. A. Construindo o futuro todos os dias. Disponível em: <http://www.tanac. com.br/PT/institucional.php?nomTbl=texto empresa\&codDado=5>. Acesso em: 11 jun. 2013. TEODORO, A. S.; LELIS, R. C. C. Colagem de madeira sólida com adesivo natural à base de tanino. 
Revista da Universidade Rural: Série Ciências da Vida, Seropédica, p. 55-59, 2005.

TRUGILHO, P. F. et al. Avaliação do conteúdo em taninos condensados de algumas espécies típicas do cerrado mineiro. Cerne, Lavras, v. 3, n. 1, p. 1 - 13, 1997.

TRUGILHO, P. F. et al. Determinação do teor de taninos na casca de Eucalyptus spp. Cerne, Lavras, v. 9, n. 2. p. 246-254, 2003.
VÁZQUEZ, G. et al. Adhesivos fenol-ureaformaldehído modificados con taninos para contrachapados de uso exterior. Información Tecnológica, La Serena, v. 16, n. 2, p. 41-46, 2005.

VITAL, B. R. et al. Avaliação dos taninos da casca de Eucalyptus grandis W. Hill ex Maiden como preservativo de madeira. Revista Árvore, Viçosa, v. 25, n. 2, p. 245 - 256, 2001. 